\title{
Right ventricular filling in dilated cardiomyopathy
}

\author{
Shinichi Fujimoto, Kim H Parker, Derek G Gibson
}

Abstract

Purpose-To assess right ventricular filling in dilated cardiomyopathy.

Patients-32 patients with dilated cardiomyopathy and 24 healthy controls.

Methods-Stroke distances were measured by pulsed Doppler echocardiography at left ventricular outflow and left and right ventricular inflow. The inflow tract dimensions of both ventricles and the outflow tract dimension of the left ventricle were measured from two dimensional images. Right and left sided atrioventricular (AV) ring excursions were measured by $M$ mode echocardiography at the tricuspid and mitral rings. Stroke volume was derived as stroke distance multiplied by left ventricular outflow tract area. Total stroke distances were calculated as the sum of $A V$ valve Doppler stroke distances and ring excursion. The effective orifice areas of the two AV valves were thus defined as stroke volumes divided by total stroke distance.

Results-Total tricuspid stroke distance was normally less than mitral $(6 \cdot 0(1 \cdot 7) v$ $7.6(1.7) \mathrm{cm}, P<0.05)$, implying that effective orifice area of the tricuspid valve was consistently greater $(6.6(1 \cdot 6) v$ $\left.4.5(0.8) \mathrm{cm}^{2}, P<0.01\right)$. Total tricuspid ring excursion was normally more than mitral $(2.30(0.30) \quad v \quad 1.62(0.22) \mathrm{cm}$, $P<0.01)$. Total tricuspid stroke distance in dilated cardiomyopathy was also less than mitral $(7.8(2.4) \quad v \quad 9.7(2.8) \mathrm{cm}$, $P<0.05)$. Tricuspid stroke distance was significantly increased in patients with dilated cardiomyopathy compared with that in healthy controls $(P<0.05 v$ controls), though stroke volume was much smaller (26 (10) $v 63$ (11) $\mathrm{ml}, \mathrm{P}<0.01)$ so that tricuspid effective orifice area was reduced to less than half normal (2.7 $\left.(1.2) \mathrm{cm}^{2}, P<0.01\right)$. Total tricuspid ring long axis excursion was more than mitral $(1.37(0.6) v 0.74(0.21) \mathrm{cm}, P<0.01)$. Right ventricular end diastolic inflow dimension was increased compared with that in healthy controls $(3.9(0.7) v 2.8$ $(0.5) \mathrm{cm}, P<0.01)$, correlating inversely with tricuspid effective orifice area $(r=-0.71, P<0 \cdot 01)$. Total tricuspid ring excursion was bimodally distributed as a low amplitude group (less than $1.6 \mathrm{~cm}$, $\mathbf{n}=23$ ) and $a$ high amplitude group (more than $1.6 \mathrm{~cm}, \mathrm{n}=9$ ), in which the interval $P_{2}$ to onset of tricuspid flow was much longer (100 (35) $v 50$ (14) ms, $P<0.01$ ). Conclusions-Enlargement of the right ventricular inflow tract in dilated cardio- myopathy, especially to more than $5 \mathrm{~cm}$, is accompanied by a progressive decrease in effective tricuspid orifice area, sometimes to less than $1 \mathrm{~cm}^{2}$ and increased inflow velocities. Right ventricular relaxation was incoordinate in $28 \%$ of the patients studied. These disturbances of right ventricular filling are likely to compromise overall cardiac function independently of left ventricular disease.

(Br Heart f 1995;74:287-292)

Keywords: dilated cardiomyopathy; right ventricular filling; echocardiography.

In dilated cardiomyopathy the left ventricle is dilated and the forward stroke volume is low. It is generally assumed that this is because of systolic disease. Pathological studies have shown a variable degree of right ventricular involvement in addition to the predominant lesions on the left. ${ }^{1}$ We have previously shown that the effective orifice area of the mitral valve may be much less than its anatomical size in such patients, causing inflow blood velocities to be greatly increased. ${ }^{2}$ In the present study, therefore, we aimed to determine the extent to which similar abnormalities might be present on the right side of the heart in patients with classical dilated cardiomyopathy on the left. In doing so, we hoped to gain some insight into the frequency and nature of disturbances of right ventricular filling in such patients, and thus the extent to which they might limit overall cardiac function.

\section{Patients and methods}

PATIENTS

Thirty-two patients with dilated cardiomyopathy (mean (SD) age 51 (9) years; 18 males and 14 females) and 24 healthy controls (mean (SD) age 46 (10) years; 11 males and 13 females), were studied. The diagnosis of dilated cardiomyopathy was made on the basis of an end diastolic left ventricular transverse dimension greater than $6.5 \mathrm{~cm}$ as measured by $\mathbf{M}$ mode echocardiography, and a shortening fraction less than 25 per cent. Patients with haemodynamically significant mitral or tricuspid regurgitation were excluded.

\section{MEASUREMENTS}

Ventricular cavity size

Echocardiographic examination was performed with a commercially available system (Toshiba SSH 160A or Hewlett-Packard model 77020 A Sonos 1000 ) operating with a 2.5 $\mathrm{MHz}$ transducer. $\mathrm{M}$ mode echocardiograms 
Figure 1 Measurements of atrioventricular ( $A V)$ ring motion with reference to Doppler flow. (A)

Measurement of coordinate right $A V$ ring motion and (B) incoordinate in dilated cardiomyopathy. Note that in the latter, more than half of $A V$ ring excursion has occurred before any tricuspid flow can be detected. $E$, total excursion of long axis; EO, excursion before onset of Doppler flow during isovolumetric relaxation; Ee, excursion in early diastole; $E a$, excursion in late diastole, ECG, electrocardiogram; $P C G$, phmocardiogram; $P_{2}$ onset of the pulmonary component of the second heart sound.
A

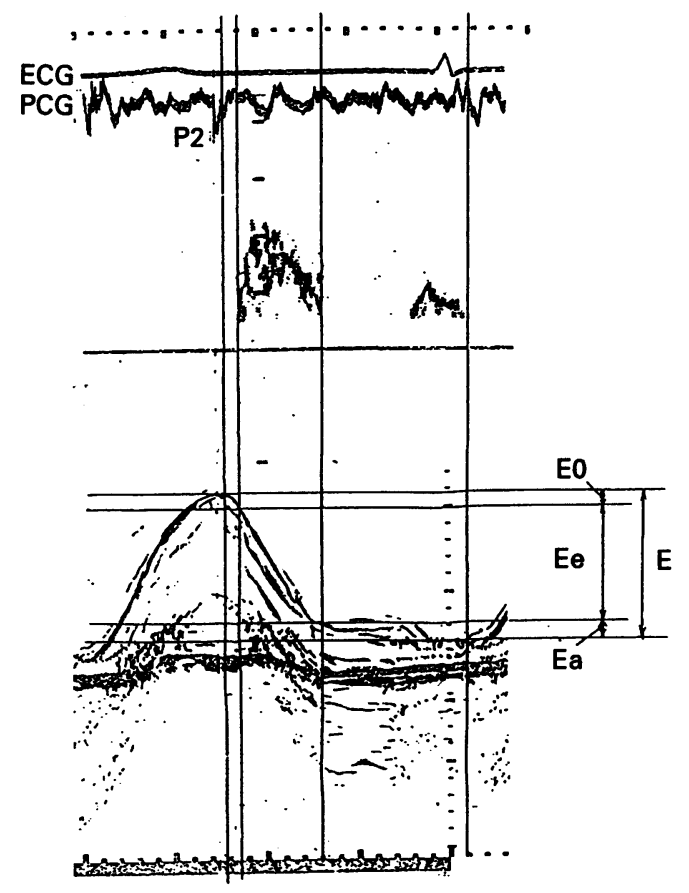

and Doppler velocity traces were recorded separately on a strip chart recorder at a paper speed of $100 \mathrm{~mm} / \mathrm{s}$ with simultaneous electrocardiogram (ECG) and phonocardiogram. On the parasternal long axis view, we measured left ventricular transverse dimension at end diastole (synchronous with the $q$ wave of the ECG) and end ejection (synchronous with $\mathrm{A}_{2}$; onset of the aortic component of the second heart sound of the phonocardiogram). The identity of $A_{2}$ and $P_{2}$ (onset of the pulmonary component of the second heart sound) were validated as the times of aortic and pulmonary valve closure on the respective echograms. On the apical four chamber view, we measured the transverse diameter of the inflow tract of both ventricles at the level of the tips of the atrioventricular valve leaflets as the distance from the septum to the endocardium of the free wall. The diameter of the left ventricular outflow tract was measured just below the aortic valve cusps.

\section{Atrioventricular ( $A V$ ) ring motion}

The motion of the two AV rings with respect to apex was measured by $M$ mode echocardiography from the apical four chamber view, with the cursor passing through the right side of tricuspid and left side of the mitral rings. Total excursion was measured along with the components occurring during early diastole and atrial systole (fig 1(a)). Early diastolic excursion, measured from the time of peak shortening until the onset of diastasis, normally coincides with the duration of the $\mathrm{E}$ wave of the AV Doppler flow velocity. In some patients with dilated cardiomyopathy, however, there is appreciable AV ring movement towards the atrium before the onset of detectable AV flow (fig 1(b)). We therefore also identified the component of AV ring atri-
B

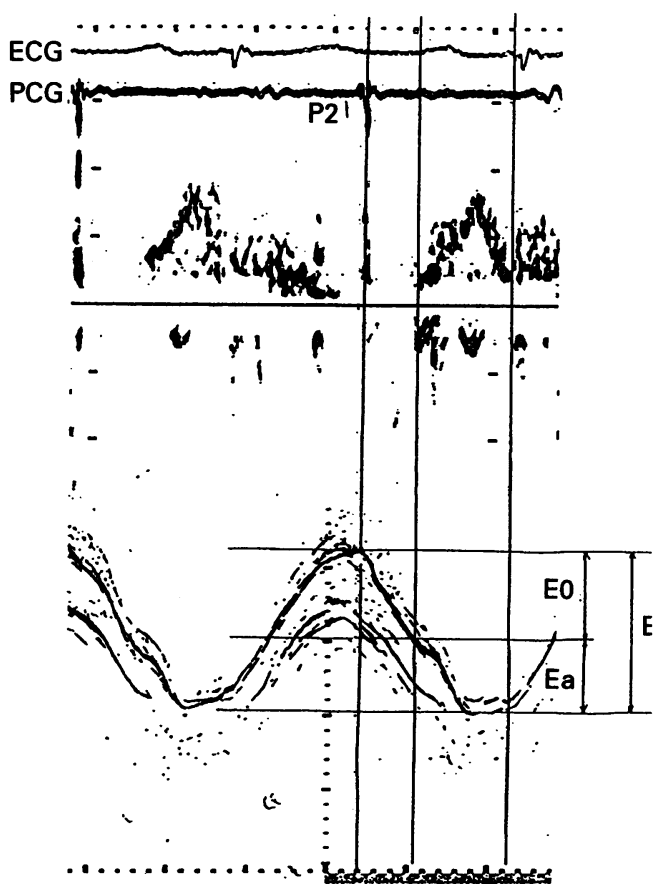

ally directed motion that was accompanied by blood flow across the valve.

Doppler echocardiography

We recorded a pulsed Doppler trace from the left ventricular outflow tract at the same level as the transverse diameter had been measured. Stroke volume was calculated as the product of left ventricular outflow tract area and aortic stroke distance, the latter derived as the time integral of the digitised trace. ${ }^{34}$ Pulsed Doppler recordings were also obtained of right and left ventricular inflow at $\mathrm{AV}$ ring level. The time intervals from $A_{2}$ to the onset of the left ventricular filling and the total duration of mitral flow were recorded on the left side, and compared with the corresponding values on the right, the interval from $P_{2}$ to the onset of tricuspid flow and total right ventricular filling time. The time integral of a flow velocity curve has the dimension of length $(\mathrm{cm})$ and thus represents a distance. Mitral and tricuspid stroke distances were calculated as the time integral of velocity over $E$ wave by computer digitisation. Stroke volume (SV) during early diastole ( $\mathrm{E}$ wave) was calculated as:

$$
\mathrm{SV} \cdot \mathrm{V}_{\mathrm{E}} /\left(\mathrm{V}_{\mathrm{E}}+\mathrm{V}_{\mathrm{A}}\right)
$$

where $V_{E}$ and $V_{A}$ are peak velocities of the $E$ and $A$ waves.

\section{Respiration}

All patients exhibited stable, natural respiration. To eliminate respiratory effects, all Doppler measurements were averaged over five full beats, which included at least one respiratory cycle. The effect of respiration on pulmonary artery flow stroke distance was further investigated in five representative normal controls and five patients with dilated cardiomyopathy. Pulmonary artery pulsed 
Doppler recordings were made with the sample volume just proximal to the pulmonary valve. Respiration was detected using a nasal thermistor. Figure 2 shows a pulmonary artery flow pulsed Doppler recording with simultaneous respiratory curve in a normal control.

\section{Effective flow orifice area}

The stroke volume entering each ventricle during diastole can be considered as consisting of two components: that detected by pulsed Doppler as blood moving with respect to a transducer at the apex, and that caused by AV ring motion where the blood remains stationary with respect to the ultrasound transducer as the ring moves around it, which is not therefore detectable by Doppler. This latter component was described as long ago as 1907 on anatomical grounds by Keith, ${ }^{5}$ and its presence has been confirmed echocardiographically since then. ${ }^{6}$ The total flow volume of the former component is the product of mitral or tricuspid stroke distance and effective orifice area; that of the latter is the product of effective orifice area and the overall amplitude of AV ring motion. Effectively, therefore, stroke volume $(\mathrm{SV})$ is:

$$
S V=A_{d} \cdot S D_{d}+A_{r} \cdot S D_{r}
$$

where $A_{d}$ and $A_{r}$ are effective orifice areas for Doppler and ring motion, $S D_{d}$ is Doppler stroke distance, and $\mathrm{SD}_{\mathrm{r}}$ total amplitude of ring motion. If we assume that $A_{d}$ is approximately equal to $A_{r}$ it follows that effective orifice area (EOA) is:

$$
\mathrm{EOA}=\mathrm{SV} /\left(\mathrm{SD}_{\mathrm{d}}+\mathrm{SD}_{\mathrm{r}}\right)
$$

Effective orifice areas were thus calculated for mitral and tricuspid valves.

Inflow jet diameter was also calculated from the effective flow orifice area (EOA) as: $2 \sqrt{ }(\mathrm{EOA} / \pi)$ assuming that the jet was circular in cross section.

\section{STATISTICAL ANALYSIS}

Values are expressed as mean (SD). Comparison between groups was carried out
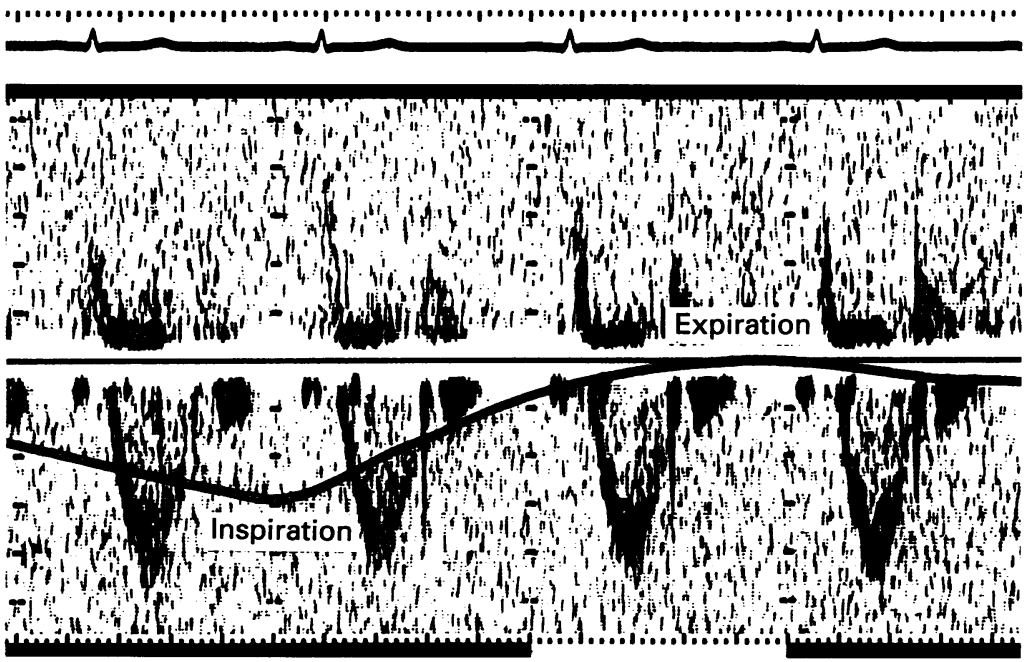

Figure 2 Right ventricular outflow pulsed Doppler recording with simultaneous respiration curve in a normal control. Downward movement of respiration trace corresponds to inspiration. (Calibration of pulsed Doppler $=20 \mathrm{~cm} \cdot \mathrm{s}^{-1}$ ). by Student's unpaired $t$ test. The $\mathrm{p}$ value was considered to be statistically significant when it was less than 0.05 . The nature of distribution within samples was investigated by constructing a normal frequency plot. ${ }^{7}$

\section{Results}

CLINICAL DATA

Left ventricular cavity size was, by definition, increased in patients with dilated cardiomyopathy. Normal inflow left and right ventricular diameters were $4.2(0.7)$ and $2.8(0.5) \mathrm{cm}$ at end diastole, and $5.7(1.1)$ and $3.9(0.7)$ $\mathrm{cm}$ in patients with dilated cardiomyopathy (table 1). Correlation coefficients between left ventricular parasternal minor axes and corresponding values of inflow diameter measured from the apical four chamber view were 0.81 at end diastole and 0.78 at end systole.

\section{DOPPLER ECHOCARDIOGRAPHIC DATA}

Normal controls

Overall stroke volume was 63 (11) $\mathrm{ml}$ in normal controls (table 1). The $\mathrm{E}$ and $\mathrm{A}$ wave velocities and corresponding stroke distances were all consistently lower on the right than on the left, so the effective orifice area of the tricuspid valve was greater, being $6.6(1.6) \mathrm{cm}^{2}$ compared with $4.5(0.8) \mathrm{cm}^{2}$ for the mitral valve (table 1). These values corresponded to 120 and 80 percent respectively of the anatomical inflow diameter of the corresponding

\begin{tabular}{|c|c|c|}
\hline & $\begin{array}{l}\text { Normal } \\
\text { controls } \\
(n=24)\end{array}$ & $\begin{array}{l}\text { Dilated } \\
\text { cardiomyopathy } \\
(n=32)\end{array}$ \\
\hline \multicolumn{3}{|l|}{ Left ventricular short axis $(\mathrm{cm})$} \\
\hline $\begin{array}{l}\text { End diastole } \\
\text { End systole }\end{array}$ & $\begin{array}{l}4 \cdot 8(0 \cdot 7) \\
3 \cdot 1(0 \cdot 5)\end{array}$ & $\begin{array}{l}6 \cdot 9(0 \cdot 5) \\
5 \cdot 7(0.9)\end{array}$ \\
\hline \multicolumn{3}{|c|}{ Left ventricular inflow tract $(\mathrm{cm})$} \\
\hline $\begin{array}{l}\text { End diastole } \\
\text { End systole }\end{array}$ & $\begin{array}{l}4 \cdot 2(0 \cdot 7) \\
3 \cdot 1(0.5)\end{array}$ & $\begin{array}{l}5 \cdot 7(1 \cdot 1) \dagger \\
5 \cdot 1(1 \cdot 2) \dagger\end{array}$ \\
\hline \multicolumn{3}{|l|}{ Right ventricular inflow tract $(\mathrm{cm})$} \\
\hline $\begin{array}{l}\text { End diastole } \\
\text { End systole }\end{array}$ & $\begin{array}{l}2 \cdot 8(0 \cdot 5) \\
2 \cdot 4(3 \cdot 4)\end{array}$ & $\begin{array}{l}3.9(0.7) \dagger \\
3.4(0.8) \dagger\end{array}$ \\
\hline \multicolumn{3}{|l|}{ Peak E wave velocity $(\mathrm{cm} / \mathrm{s})$} \\
\hline $\begin{array}{l}\text { Mitral } \\
\text { Tricuspid }\end{array}$ & $\begin{array}{l}67(18) \\
26(5) \oint\end{array}$ & $\begin{array}{r}102(22) \dagger \\
44(9)+5\end{array}$ \\
\hline \multicolumn{3}{|l|}{ Peak A wave velocity $(\mathrm{cm} / \mathrm{s})$} \\
\hline $\begin{array}{l}\text { Mitral } \\
\text { Tricuspid }\end{array}$ & $\begin{array}{l}56(12) \\
18(7) \S\end{array}$ & $\begin{aligned} 9(10) \dagger \\
11(11)^{\star}\end{aligned}$ \\
\hline \multicolumn{3}{|l|}{ Abnormal filling pattern: } \\
\hline $\begin{array}{l}\text { Mitral } \\
\text { Tricuspid } \\
\text { Stroke volume (ml) }\end{array}$ & $\begin{array}{c}0 / 24 \\
0 / 24 \\
63(11)\end{array}$ & $\begin{array}{l}27(\mathrm{E}), 5(\mathrm{~S}) / 32 \\
16(\mathrm{E}), 13(\mathrm{~S}) / 32 \\
26(10)+\end{array}$ \\
\hline \multicolumn{3}{|c|}{ Pulsed Doppler stroke distance $(\mathrm{cm})$} \\
\hline $\begin{array}{l}\text { Mitral } \\
\text { Tricuspid }\end{array}$ & $\begin{array}{l}6.5(1.7) \\
4.3(0.9)\end{array}$ & $\begin{array}{l}9 \cdot 6(3 \cdot 4) \dagger \\
7 \cdot 0(2 \cdot 0)^{\star} S\end{array}$ \\
\hline \multicolumn{3}{|l|}{ Total stroke distance } \\
\hline $\begin{array}{l}\text { Mitral } \\
\text { Tricuspid }\end{array}$ & $\begin{array}{l}7 \cdot 6(1 \cdot 7) \\
6 \cdot 0(1 \cdot 7) \ddagger\end{array}$ & $\begin{array}{l}9 \cdot 7(2 \cdot 8) \dagger \\
7 \cdot 8(2 \cdot 4)^{\star}\end{array}$ \\
\hline $\mathbf{R}-\mathbf{R}$ interval (ms) & $800(130)$ & $650(130) \dagger$ \\
\hline ling time (ms) & & \\
\hline $\begin{array}{l}\text { Tricuspid filling time (ms) } \\
A_{2} \text { to onset of mitral flow (ms) } \\
P_{2} \text { to onset of tricuspid flow (ms) }\end{array}$ & $\begin{array}{l}385(150) \\
80(12) \\
\text { s) } 68(22) \$\end{array}$ & $\begin{array}{l}245(45) \dagger \\
67(22) \dagger \\
75(45)\end{array}$ \\
\hline $\begin{array}{l}\text { Mitral effective flow orifice } \\
\text { area }\left(\mathrm{cm}^{2}\right)\end{array}$ & $4 \cdot 5(0 \cdot 8)$ & $2 \cdot 5(0 \cdot 8) \dagger$ \\
\hline $\begin{array}{l}\text { Tricuspid effective flow orifice } \\
\text { area }\left(\mathrm{cm}^{2}\right) \text {. }\end{array}$ & $6.6(1.6)$ & $2 \cdot 7(1 \cdot 2) \dagger$ \\
\hline \multicolumn{3}{|c|}{$\begin{array}{l}\text { Mitral effective inflow jet diameter as } \\
\% \text { left ventricular inflow }\end{array}$} \\
\hline $\begin{array}{l}\text { Tricuspid effective inflow jet dia } \\
\text { as \% right ventricular inflow } \\
\text { (ES) }(\%)\end{array}$ & $120(36)$ & $55(25)+5$ \\
\hline
\end{tabular}

Table 1 Doppler echocardiographic measurements

${ }^{*} P<0.05 ;+P<0.01 v$ normal controls. $\ddagger P<0.05 ; \emptyset P<0.01$, right $v$ left side. $E, E$ wave filling pattern; $S$, summation filling pattern (superimposed $\mathbf{E}$ and $\mathrm{A}$ wave); ES, end systole. Student's unpaired $t$ test. 
Table 2 Atrioventricular ring motion

\begin{tabular}{|c|c|c|}
\hline & $\begin{array}{l}\text { Normal } \\
\text { controls } \\
(n=24)\end{array}$ & $\begin{array}{l}\text { Dilated } \\
\text { cardiomyopathy } \\
(n=32)\end{array}$ \\
\hline \multicolumn{3}{|c|}{ Total excursion $(\mathrm{cm})$} \\
\hline Mitral & $1.62(0.22) \dagger$ & $0.74(0.21)^{\star} t$ \\
\hline Tricuspid & $2.30(0.30) \dagger$ & $1.37(0.60)^{\star} \dot{\dagger}$ \\
\hline \multicolumn{3}{|c|}{ Excursion before onset of flow (cm) } \\
\hline Mitral & $0.06(0.08)$ & $0.10(0.20) \dagger$ \\
\hline Tricuspid & $0.13(0.17)$ & $0.42(0.36)^{\star} t$ \\
\hline \multicolumn{3}{|c|}{ Excursion in early diastole $(\mathrm{cm})$} \\
\hline Mitral & $1.09(0.20)$ & $0.46(0.17)^{\star} t$ \\
\hline Tricuspid & $1.26(0.33)$ & $0.83(0.39)^{\star}+$ \\
\hline \multicolumn{3}{|c|}{ Excursion in atrial systole $(\mathrm{cm})$} \\
\hline Mitral & $0.45(0.24)$ & $0.18(0 \cdot 15)^{\star}$ \\
\hline Tricuspid & $0.92(0.42)$ & $0.12(0.31)^{\star}$ \\
\hline
\end{tabular}

${ }^{\star} \mathrm{P}<0.01 v$ normal controls; $+\mathrm{P}<0.01$ right $v$ left side. Student's unpaired $t$ test.
Figure 3 Relation orifice area of the tricuspid valve and right ventricular end diastolic inflow dimension. The linear regression line is $y=-2 \cdot 1 x+12$, $r=-0 \cdot 71$. Standard deviations of slope and intercept are 0.68 and 2.4 $\mathrm{cm}^{2}$. Standard error of estimate is $1.1 \mathrm{~cm}^{2}$. between effective flow

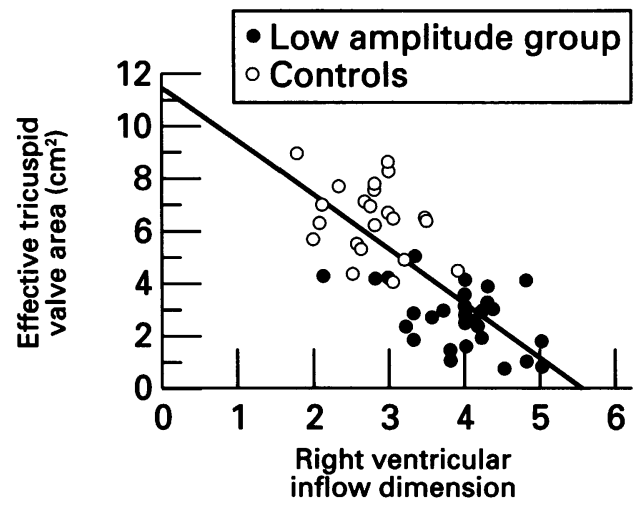
1.4. Standard error of
Figure 4 Relation between effective flow orifice area of the tricuspid valve and total excursion of the tricuspid atrioventricular $(A V)$ ring. The linear regression line is $y=0.21 x+0.4$, $r=0.65$. Standard deviations of slope and deviations of slope and
intercept are 0.085 and estimate is 1.0 .

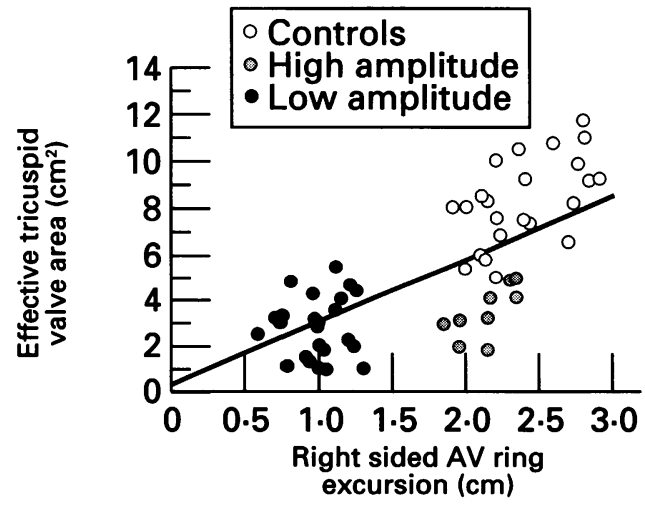

Figure 5 Normal distribution plot of total excursion of right atrioventricular ( $A V$ ) ring in patients with dilated cardiomyopathy. $r=0.936, r_{0.01}=0.972$ $(n=32)$. The distribution of values is clearly bimodal, with a cut off value of approximately $1.6 \mathrm{~cm}$. ventricles. There were further minor differences between the two ventricles in that onset of tricuspid flow was consistently earlier than that across the mitral valve by about $20 \mathrm{~ms}$, and the overall amplitude of right $\mathrm{AV}$ ring total excursion was 40 percent greater than that of the left (table 2).

\section{DILATED CARDIOMYOPATHY}

Stroke volume was greatly reduced in these patients to $26(10) \mathrm{ml}$ (table 1). In addition, filling pattern was almost invariably abnormal on both sides of the heart, with either a greatly reduced or absent A wave, or there was a summation filling pattern. Peak E wave velocities were higher on both sides of the heart and total stroke distances were longer, the overall extent of these changes being closely similar in the right and left ventricles (table 1). As a result, effective orifice area of the tricuspid valve was reduced almost to the same extent as that of the mitral valve (table 1 ). Both were much smaller than normal, when expressed in absolute terms, and even more so when compared to end systolic inflow diameter. At the same time, the overall amplitude of right $\mathrm{AV}$ ring motion was reduced (table 2 ), and a greater proportion of lengthening occurred before the onset of flow than in normal controls.

\section{Interrelations between variables}

There was clear inverse correlation between right ventricular inflow diameter and effective orifice area (fig 3), the intercept of which suggests that orifice area would become very small when inflow diameter was greater than $5.5 \mathrm{~cm}$. There was considerable overlap between normal and abnormal values when overall right $\mathrm{AV}$ ring excursion was correlated with effective orifice area (fig 4). A very clear bimodal pattern emerged however, when a normal frequency plot was made of the extent of total right sided AV ring excursion $\left(r=0.936, r_{0.01}=0.972\right)$. Patients divided themselves into two groups, with a cut off value of $1.6 \mathrm{~cm}$ (fig 5). Comparison of these two groups showed that when the amplitude of right sided AV ring excursion was $>1.6 \mathrm{~cm}$ significant lengthening occurred before the onset of detectable tricuspid flow-that is, during the period of isovolumetric relaxation. This incoordinate $\mathrm{AV}$ ring excursion was less extensive $(0.23(0.19) \mathrm{cm})$ in patients in whom the overall amplitude was below $1.6 \mathrm{~cm}$ versus $0.80(0.31) \mathrm{cm}$ in those in whom it was greater $(P<0.01)$. The asynchrony arose because the onset of flow across the valve was delayed with respect to $P_{2}$ by 50 (14) ms in the former group and by 100 (35) in the latter, while the time of onset of AV ring motion itself was normal in both. The overall characteristics of the two groups were otherwise similar.

\section{Effects of respiration}

Respiratory effects were small. Pulmonary artery stroke distance increased by a mean of 4.3 percent of inspiration in controls and $5 \cdot 2$ percent in patients with dilated cardiomyopathy. 
As subpulmonary cross sectional area can be assumed to be effectively constant throughout the respiratory cycle changes in right ventricular stroke volume were correspondingly low.

\section{Discussion}

Dilated cardiomyopathy is a condition defined in terms of abnormalities of left ventricular cavity size and shape. End diastolic volume is increased, stroke volume low, and ejection fraction greatly reduced. The resulting clinical picture is generally held to be directly caused by depressed left ventricular systolic function; an additional contribution from the right ventricle is not usually invoked. Indeed, there are considerable practical problems in diagnosing right ventricular disease in the presence of such marked abnormalities on the left. A low stroke volume and increased pulmonary artery pressure caused by raised filling pressures on the left will combine to reduce right ventricular ejection fraction. Right ventricular diastolic function will also be disturbed by ventricular interaction ${ }^{89}$ as well as by fluid retention which will raise cavity pressure. It is not surprising, therefore, that the question of the presence and nature of additional disease of the right ventricle in such patients has received little consideration in the literature. Despite these problems there are indications that right ventricular disease may be present. Right ventricular myocardium can be shown pathologically to be affected in the same way as that on the left. ${ }^{10}$ Right ventricular ejection fraction may be reduced, and a low filling rate has been demonstrated by radionuclide angiography ${ }^{11-13}$ and magnetic resonance imaging. ${ }^{14}$

In the present investigation, we studied right ventricular function from the point of view of the dimensions and some of the properties of the incoming flow during early diastole, an approach that has previously shown very clear differences between normal and abnormal ventricles on the left side of the heart in dilated cardiomyopathy. ${ }^{2}$ On the right side, the normal inflow jet has a large cross sectional area, significantly greater than that on the left, with the result that inflow velocities and stroke distances are significantly lower. It was thus of interest to note that the inflow dimension of the right ventricle was also significantly larger than on the left, though the ratio of jet area to that of the inflow tract was about 120 percent for right and 80 percent for left side. This finding is in line with that of Tei et $a l^{15}$ who demonstrated the anatomical diameter of the tricuspid ring to be significantly larger than that of the mitral, and also with our finding that the amplitude of long axis motion was also greater. The characteristics of right ventricular filling thus differ from those on the left; with a larger jet area, normal volume filling rates can be achieved with lower blood velocities and accelerations, and thus with a lower pressure drop along the jet.

The main criterion for diagnosing dilated cardiomyopathy is an end diastolic cavity dimension greater than the upper 95 percent confidence limit of normal. Not surprisingly, therefore, on the left side there was no overlap between patients and healthy controls. On the right side, however, this was not the case, and in 11 of 32 patients with dilated cardiomyopathy inflow diameter was less than the upper 95 percent confidence limit of normal. It was thus possible to study a wider span of right ventricular involvement than on the left. Despite this, we were able to demonstrate filling disturbances on the right side of the heart that were almost identical to those we have previously seen on the left. The pattern of filling was altered, with either a dominant $\mathrm{E}$ wave or a summation filling pattern in virtually all patients. Right ventricular filling time was frequently reduced to values approaching $200 \mathrm{~ms}$. Finally, the right sided filling jet was modified in the same way as on the left. Although stroke volume was greatly reduced, peak early diastolic filling velocities and stroke distances were consistently increased, showing that the effective orifice area of the tricuspid valve was greatly reduced, both in absolute terms, and even more so when expressed as a ratio of the dimension of the enlarged inflow tract. Furthermore, the extent of this abnormality was inversely related to the extent of the anatomical disturbance as assessed by right ventricular inflow diameter.

A study such as this clearly has limitations. All right sided events are potentially affected by respiration to a greater degree than those on the left, ${ }^{16}{ }^{17}$ therefore we averaged all measurements over five beats to encompass a respiratory cycle, although direct measurement at pulmonary artery level showed respiratory effects to be small. The approach to estimation of the component of stroke volume due to AV ring motion has been used previously, ${ }^{6} 18$ and is likely to be satisfactory in normal controls. Its applicability in patients with dilated cardiomyopathy is less clear, however, as we have no direct evidence that effective orifice areas are the same for the AV jet as they are for ring motion. This problem will cause little error in those cases in which the amplitude of ring motion is small. This may cause ambiguity, however, when the amplitude is larger as, although we demonstrated that the amplitude of ring motion during tricuspid filling was small, we have not definitively proved that ventricular volume did not increase in the absence of forward flow during the remainder of early diastole. This effect, if present, would reduce the component of stroke volume accounted for by Doppler, and thus would have led to an overestimation of effective orifice area by $10-20$ percent.

The right ventricle is much less accessible to study by echocardiography than the left, and its shape is more complex. ${ }^{19} 20$ We therefore used inflow tract dimension which can be determined from the apical four chamber view as an index of cavity dilatation. On the left side, the corresponding value agrees reasonably well $(r=0 \cdot 80)$ with values of the minor axis obtained from the parasternal $M$ mode echocardiogram that are used as the diagnostic 
criterion for the condition. Unlike the left ventricle, however, the right ventricular cavity is not circular in cross section, particularly in healthy controls. This difference may well explain the values of the jet area to inflow area of more than 100 percent; the cavity can be better approximated as being elliptical in cross section, with the inflow dimension representing its minor axis. Finally, the right ventricle has a clearly developed outflow tract, the infundibulum, which we did not consider in our study.

Our results seem to have clinical and physiological implications. They suggest that mechanisms underlying filling of the normal right ventricle differ qualitatively from those on the left. Inflow velocities and thus stroke distances are lower, effective orifice area is larger, and the contribution of ring motion to stroke volume is greater. These findings are all compatible with the idea that normal right ventricular filling is accomplished with significantly lower pressure gradients along the direction of flow than those normally seen on the left. We have little information as to the basic mechanisms underlying this difference between the two ventricles, nor indeed whether ventricular restoring forces are involved at all on the right. Nevertheless, this difference in function is likely to be related to the very different structure of the right ventricle. It may also underlie the well known problems of tricuspid valve surgery, where the effects of minor stenosis, whether caused by naturally occurring valve disease or associated with a prosthesis, are much greater on the right. This pattern changes in dilated cardiomyopathy. The amplitude of wall motion falls and inflow velocities increase indicating that the effective orifice area has decreased These increased velocities, often associated with reduced filling time, require increased accelerations and thus pressure gradients. We have previously shown that in some patients with dilated cardiomyopathy, this effect may dominate the venous pulse. ${ }^{21}$ The cause of these disturbances is still not clear, but in part their presence was closely associated with an increase in inflow tract dimension, and also with a reduction in the amplitude of long axis motion during early diastolic filling. A further finding was the presence of changes in right ventricular cavity shape during isovolumetric relaxation. On the left side of the heart such shape changes interfere with early diastolic filling ${ }^{22}$ and it is likely that the same applies on the right.

In summary, therefore, it appears that the normal pattern of right ventricular filling is usually disrupted in patients with dilated cardiomyopathy. These disturbances are similar in nature to those previously documented in this condition on the left side of the heart, but their clinical significance on the right may be increased by the characteristic "low velocity" conditions under which right ventricular filling normally occurs. In an appreciable minority of patients, therefore their presence may possibly dominate the clinical picture. In addition, with the right ventricle becoming effectively unfillable with an inflow diameter of more than $5.5 \mathrm{~cm}$, the possibility arises that mechanical aspects of right ventricular filling may underlie the deleterious effect of right ventricular enlargement on prognosis. ${ }^{23} \mathrm{We}$ have previously suggested that a similar mechanism may apply on the left. ${ }^{24}$ These abnormalities of right ventricular function seem worthy of more than the scant attention that they have hitherto received in the literature.

1 Olsen EG. Special investigation of COCM: endomyocardial biopsies (morphological analysis). Postgrad Med 1978;54:486-90.

2 Fujimoto $S$, Parker $K$, Inge KSK, Gibson DG. Reconstruction of early diastolic pressure field based on local E wave accelerations [abstract]. Br Heart $\mathcal{f} 1994$ 71:79.

3 Lewis JF, Kuo LC, Nelson JG, Limacher MC, Quinones MA. Pulsed Doppler echocardiographic determination of stroke volume and cardiac output: clinical validation of two new methods using the apical window. Circulation 1984;70:425-31.

4 Ihlen $H$, Amlie JA, Dale J, Forfang $K$, Nitter-Hauge $S$, Otterstad JE, et al. Determination of cardiac output by Otterstad JE, et al. Determination of cardiac output by

5 Keith A. An account of the structures concerned in the production of the venous pulse. F Anat Physiol 1907;42. $1-25$.

6 Jones CJH, Raposo L, Gibson DG. Functional importance of the long axis dynamics of the human left ventricle. $B$ Heart f 1990;63:215-20.

7 Cruze E, Hartzell B. Normal probability plots In: Cruze Hartzell B, eds. Minitab reference manual release $8 P$ version. Pennsylvania: Minitab 1991:4·8.

8 Santamore WP, Lynch PR, Meier G, Heckman J, Bove AA. Metween the ventricles. f Appl Physiol 1976;4:362-8.

9 Taylor R, Covell JW, Sonnenblick EH, Ross J Jr. Dependence of ventricular distensibility on filling of the opposite ventricle. Am ₹ Physiol 1967;213:711-8.

10 Richardson PJ, Olsen EGJ, Jewitt DE, Oram $S$ Percutaneous technique of left ventricular biopsy, and

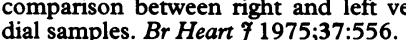

11 Caglar N, Araki H, Nagata Y, Hisano R, Fukuyama T, Nakamura $M$. Evaluation of right ventricular function in patients with idiopathic dilated and ischemic cardiomyopathy by equilibrium radionuclide ventriculography. fpn Heart f 1986;27:1-9.

12 Lomuscio A, Benaglia D, Mana O, Boccolari S, Marino V. Radionuclide angiographic assessment of right ventricula function in patients with idiopathic dilated and ischemic cardiomyopathy. Med Sci Res 1987;15:517-8.

13 Kubota S, Kubota S, Iwase T, Iizuka T, Imai S, Suzuki T, et al. Right ventricular function in patients with dilated cardiomy thy: as pool scintigraphy. F Cardiol 1993;23:157-64 (partly in pool scintigra

14 Suzuki J, Caputo GR, Masui T, Chang JM, O'Sullivan M, Higgins CB. Assessment of right ventricular diastolic and systolic function in patients with dilated cardioand systolic function in patients with dilated cardiomyopathy using cine magn

15 Tei C, Pilgrim JP, Shah PM, Ormiston JA, Wong M Tricuspid valve annulus: study of size and motion in normal subjects and in patients with tricuspid regurgitation. Circulation 1982;66:665-71.

16 Hatle LK, Appleton CP, Popp RL. Differentiation of constrictive pericarditis and restrictive cardiomyopathy by Doppler echocardiography. Circulation 1989;79:357-70.

7 Riggs TW, Snider AR. Respiratory influence on right and left ventricular diastolic function in normal children. $A m$ $f$ Cardiol 1989;63:858-61.

18 Isaaz $K$, del Romeral LM, Lee E, Schiller NB Quantitation of the motion of cardiac base in normal subjects by Doppler echocardiography. f Am Soc Echocardiogr 1993;6:166-76.

19 Kaul S, Tei C, Hopkins JM, Shah PM. Assessment of right ventricular function using two-dimensional echocardiography. Am Heart $\mathcal{f}$ 1984;107:526-31.

20 Cohen $M$, Fuster V. What do we gain from the analysis of right ventricular function? $¥ \mathrm{Am}$ Coll Cardiol 1984;3 right vent $1082-4$.

21 Lee CH, Xiao HB, Gibson DG. Jugular venous "a" wave in dilated cardiomyopathy: sign of abbreviated right vendilated cardiomyopathy: sign of abbreviated righ

22 Brecker JD, Lee CH, Gibson DG. Relation of ventricular isovolumic relaxation time and incoordination to transisovolumic relaxation time and incoordination

23 Sun JP, James KB, Miller DP, Solanni N, Shah MS, Lee $\mathrm{K}$, et al. Right ventricular enlargement predicts mortality and progression of ventricular function in dilated cat diomyopathy [abstract]. Circulation 1994;90:I-549.

$24 \mathrm{Ng} \mathrm{KSK}$, Gibson DG. Impairment of diastolic function by shortened filling period in severe left ventricular disease. Br Heart $\mathcal{1}$ 1989;62:246-52. 